ISSN 2767-3901

\title{
On the Development of a Small Plutonium-Powered Bicycle
}

\author{
International Journal of Theoretical \& Computational Physics
}

Perspective Article

Florent Pirot

Unaffiliated researcher, France
*Correspondence author

\section{Florent Pirot}

Unaffiliated researcher

France

Submitted : 5 Jun 2021 ; Published : 19 Jun 2021

\begin{abstract}
A nuclear concept for two-wheeled drive is presented. Its development process is discussed. This nuclear motorbike relies on Fermionic condensation for a subcritical propulsion.
\end{abstract}

\section{Presentation of the concept}

This concept requires the use of plutonium 239 dissolved in water to ensure fittability. It shall come as a reactor-grade mix, with Pu240 for spontaneous fission. Indeed this is the easiest for industrial chaining of production, with the most available nuclear power source.

The obvious initiator of the chain reaction is the use, with own foot power typically. It is ideal to have the motor directly under the body, so the user can feel the level of heat. The foot will press on a pedal linked to an initial disk that spins the star wheel central to the scheme. The fission reaction happens typically, nevertheless in the top tube. It is a Fermionic condensation area that will sustain the advancing power of the bike, like a small in vitro fireball whose energy is being pumped for moving purposes.

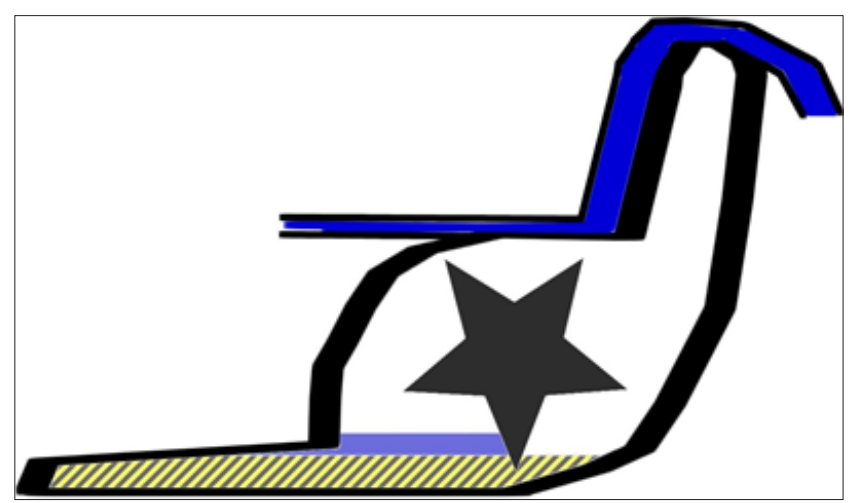

The heat not transferred by the subsequent mechanical wheel, or series of (with a switch of tubes to allow change of gear) may in some cases be given back to the bottom part of the dissolved plutonium, on the decision of the manufacturer that will have to include other coldening ways for the core (or alternatively for four-wheeled drive or, alternatively snow melting by flushing some of the water of the secondary cycle out).

Fermionic condensation contributes to keeping the fission activity in the top tube, which, it is recommended, should be near the head of the user (who, in the profile drawing presented should be looking to the right - the chain has to be inverted for trigger, and a single push to dispel the energy transfer and allow autonomous working i.e. free spinning of the wheel, natural fission only).

This product can be used for car propulsion as well of course. The star wheel is presented wide for resiliency. It can be spun only in a single direction and will spin free to let the water vapour downfall to the rear during these progressive cooling periods.

The user's initial energy decides of the level of fission actually happening in the top tube. The user's initial energy starts the fission chain in the top tube. The user behaves at its own responsibility and has to understand the levels of « inertia » of the in vitro fireball.

Two layers of martensitic steel could be an ideal way to shape the core of the bicycle. $\mathrm{Pb}$ could be left only at $98 \%$ (i.e. at some point only martensitic steel, without armouring) to allow more neutron evacuation.

\section{Development process}

Computer siderurgy of the frames can happen, with a series of molded panels to offer three frames to be brought together. The drawing only presents the central one. The other frames close it, in the development of a typical two-wheeled vehicle. Of course, the more complex the patterns of intrication between the frames before welding the more efficient and it is recommended:

1. The bringing of the central frame together with one of the two others and use of two coming together jets to melt down the metal slowly (while putting one or two robots aspiring air with suction pads, to hold the three frames altogether, that are sacrificated to be boiled as part of the reaction, the parenthesis here represent the two main vertical frames, Pu239/240 and water inserted through a tiny hole on top later closed by the same welding. The airsucking robot has not to be confused with the star 
compressor that is the main motor of the design but it is possible that a way could be found to merge both into a single entity).

2. The deposition of small plutonium particles, and their water

3. The immediate completion by bringing the third frame and using a single jet to melt down on the other side, the simple reaction between the plutonium and water will do the needed work inside.

An inner lead $(\mathrm{Pb})$ layer for neutron and gamma containment into two layers of martensitic steel could be an ideal way to shape the core of the bicycle. $\mathrm{Pb}$ could be left only at $90 \%$ (i.e. at some point's only martensitic steel, without armouring) to allow more neutron evacuation and the ideal way is to select, for these points:

1. the top of the pipe

2. the area above the star wheel

The produced machine should include instead of a sole propulsion system a dual propulsion also tied to an electricity production, the machine at rest produces electricity with latent heat, it is used to spin the wheel more and boost the nuclear core when decided by the user through a computer on the panel. That computer should imperatively be kept out of all networks (no bluetooth, no wifi chip or any other kind of) for obvious safety reasons.

Fermionic condensation is explained in [1]. Fermionic condensation will depend on the amount of fissile material inserted. The material used is of course a strong neutron container. Heat and radioactivity conjugate in the pipe. Capillarity too. Initial compression by the user with star spinning creates a compression at the top of that pipe that secures a fission level which creates heat - some of the heat is redistributed by the core but not all of it, contributing to maintaining the cycle.

Water is essential for the secondary cycle.

An extended drawing allows to present the main application, with a bicycle having a rear wheel much smaller but this is helping for the balance as the weight is mostly near the front. In the secondary cycle, the axis of capture of the waterflow are kept soft because it is possible to take a slightly permeable material (fiber carbon for instance) to ensure lightness, essential here.

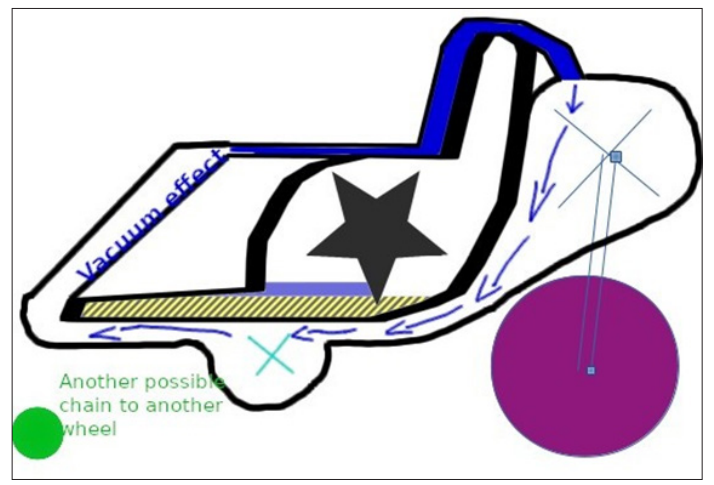

Hemp fiber could be used for the chains because of its tightness. An experiment could involve using first hemp for the rear chain and if working also use it for the front chain. Simple channeling (ladder-like) of the hemp wire into the gear of the wheel.

Combination with at-home gears for captation of latent wheel rotation into home electricity production could also be thoughtof.

\section{Conclusion}

The pure casting of the frame with molten lead (without steel) without the phases, in a ceramic lost wax, could better the solidity, while also making for heavier cores. Alternatively the use of Mandelbrot structures for the intrication of the three frames is recommended by the author altogether with very hot welding with sodium flame.

Each produced bicycle or car has to be compensated by carbon dioxide releases in the atmosphere (see [2] for details, reducing carbon dioxide emissions by manufacturing plutonium cars or bicycles replacing carbon dioxide emissions-inducing motors has to be compensated, to feed trees and other plants). This bicycle or car is only for countries where individual gun rights are established (i.e., for France, only for users who own a firearm license). Producing companies have to evaluate by themselves the amount of $\mathrm{Pu} 239$ dissolved in water, that nevertheless certainly does not go above 400 grams, with 150 grams of $\mathrm{Pu} 240$.

\section{Reference}

1. Contamination with Natural Radioactivity and Other Sources of Energy - the Explanation for Bose- Einstein Condensates, for the Creeping Behaviour of Helium and for the "Casimir Effect", International Journal of Physics. 2019, 7(3): 95-96. doi: 10.12691/ijp-7-3-5.

2. Florent Pirot. Volcanic Tephras and Human Energy Losses Together: The Real Source of Climate Change. International Journal of Physics. 2019; 7(4):126-134. doi: 10.12691/ijp-7-4-3

Copyright: (C2021 Florent Pirot. This is an open-access article distributed under the terms of the Creative Commons Attribution License, which permits unrestricted use, distribution, and reproduction in anymedium, provided the original author and source are credited. 